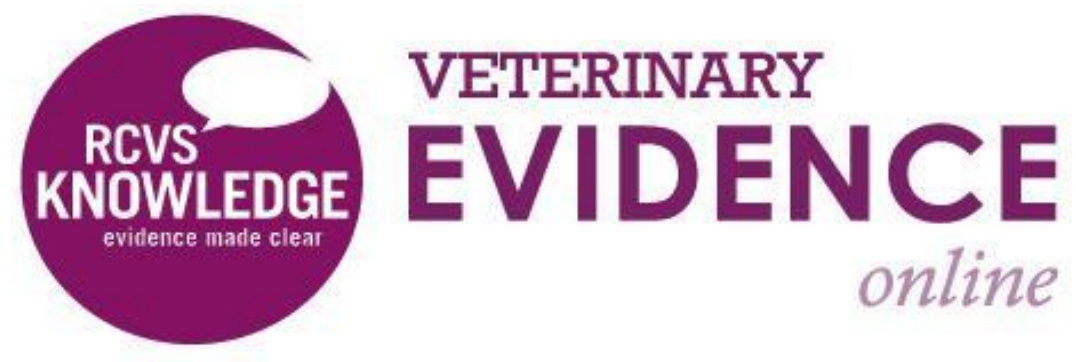

\title{
Are Pressure Vests Beneficial at Reducing Stress in Anxious and Fearful Dogs?
}

A Knowledge Summary by

Louise Anne Buckley PhD, RVN *

Corresponding Author (louisebuckleydyson@msn.com)

ISSN: 2396-9776

Published: 02 Mar 2018

in: Vol 3, Issue 1

DOI: http://dx.doi.org/10.18849/ve.v3i1.152

Reviewed by: Sue Badger (MEd, Cert Ed, RVN) and Erik Fausak (MSLIS, MA, CVT, LVT, RLAT)

Next Review Date: 02 Sep 2020 


\section{PICO question}

In fearful or anxious dogs does wearing a pressure vest, compared to not wearing one, result in reduced behavioural and physiological signs of stress?

\section{Clinical bottom line}

Four studies of variable quality and limitations were identified that investigated the use of pressure vests, using various physiological and behavioural proxy measures of anxiety. Most behavioural outcome measures associated with a positive effect were subjective assessments, with unblinded assessors. Subjectively, many of the owners believed that pressure vests had a positive effect on their dogs' anxiety levels.

The take home message for the veterinary professional is that pressure vests may have small but beneficial effects on canine anxiety and that habituating the dog to the vest, assessing for comfort and using repeatedly may improve the likelihood of any benefit. However, the owner should be cautioned that they should not expect their dog's anxiety to be fully alleviated or prevented, and it may have no beneficial effect at all.

\section{Clinical Scenario}

During veterinary nursing clinics, the veterinary nurse encounters dogs that the owners describe as being fearful, anxious or stressed in a range of situations (e.g. separation anxiety, noise phobia, etc). Aware that there is a plethora of products available on the market aimed at reducing negative emotional states in dogs, she is keen to ensure that she only recommends products to these clients when there is evidence to support their use. A couple of clients have mentioned the use of pressure vests and have suggested that the veterinary practice stock them for use with other clients, therefore she decides to examine the evidence base for these products.

\section{The Evidence}

Three studies were identified (Cottam et al., 2013; King et al., 2014; Pekkin et al., 2016) that specifically aimed to test the efficacy of commercially available pressure vests at reducing indices of stress in canines. Of these, only one (Pekkin et al., 2016) reported measuring and standardising the pressure exerted by the vests, the other two papers reported fitting (or asking owners to fit) the vests firmly in accordance with the manufacturers' instructions. On this basis, a fourth paper (Fish et al., 2017) that looked at the effect of fitting a telemetry vest (the authors report snuggly fitting these spandex vests) on physiological and behavioural parameters of dogs exposed to a stressor was also included. A fifth paper (Cottam and Dodman, 2009) was identified that also used an item of torso clothing (a cape) to use reduce stress in dogs naturalistically exposed to thunderstorms. However, this study was devised to examine the effects of an anti-static lining, and both the control and the experimental dogs wore capes (both of which reduced the anxiety levels of dogs exposed to thunderstorms). Furthermore, the authors do not report fitting the cape firmly (or any other adjective to indicate that the cape exerted pressure on the torso). Thus, this paper was not included in the evidence summary. 


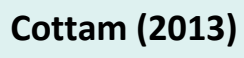




\begin{tabular}{|c|c|}
\hline & $\begin{array}{l}\text { an overall effectiveness score, reducing the sample for this section } \\
\text { to } 19 .\end{array}$ \\
\hline Intervention details: & $\begin{array}{l}\text { The intervention evaluated for efficacy at reducing anxiety during } \\
\text { thunderstorms was the commercially available Anxiety Wrap } \\
\text { (Animals Plus LLC, Huntington, IN), and animals were used as their } \\
\text { own control in a before treatment/during treatment clinical trial. } \\
\text { Study design: } \\
\text { The clinical trial was divided into two phases: } \\
\text { 1. Baseline phase (control/no treatment during two } \\
\text { thunderstorms) } \\
\text { 2. Treatment phase (experimental phase/pressure vest worn } \\
\quad \text { during five thunderstorms) } \\
\text { Owners completed a questionnaire after each thunderstorm, that } \\
\text { asked the owner to provide the following information: } \\
\text { a) The existence and severity of specific anxiety behaviours } \\
\text { (except escape/damage) listed in the inclusion criteria. } \\
\text { b) Interactions with their dog during the thunderstorm } \\
\text { c) Severity of the thunderstorm } \\
\text { Owners of dogs included were requested to discontinue (for the } \\
\text { duration of the study) any other treatments they currently used for } \\
\text { the treatment or management of thunderstorm fear. } \\
\text { Post-trial: } \\
\text { Owners were asked to complete a survey that assessed how } \\
\text { effective they felt the Anxiety Wrap was at reducing their dog's } \\
\text { thunderstorm phobia. } \\
\text { Further information: } \\
\text { Sample selection: } \\
\text { The first } 32 \text { dogs whose owners responded to the newsletter advert } \\
\text { and who met the inclusion criteria were included in this study. } \\
\text { Exposure to the Anxiety Wrap: } \\
\text { Owners were provided with an Anxiety Wrap given directions on } \\
\text { how to fit and remove it and instructed to fit it during } \\
\text { thunderstorms. They were also asked to practice fitting it once } \\
\text { before a thunderstorm (and to associate its fitting with a reward for } \\
\text { the dog) and three times during non-stormy days (to prevent the } \\
\text { dog associating the vest with thunderstorms). }\end{array}$ \\
\hline Study design: & Clinical trial \\
\hline Outcome studied: & $\begin{array}{l}\text { The main three outcome measures relevant to answering this PICO } \\
\text { were: } \\
\text { 1. Thunderstorm Anxiety Score }\end{array}$ \\
\hline
\end{tabular}




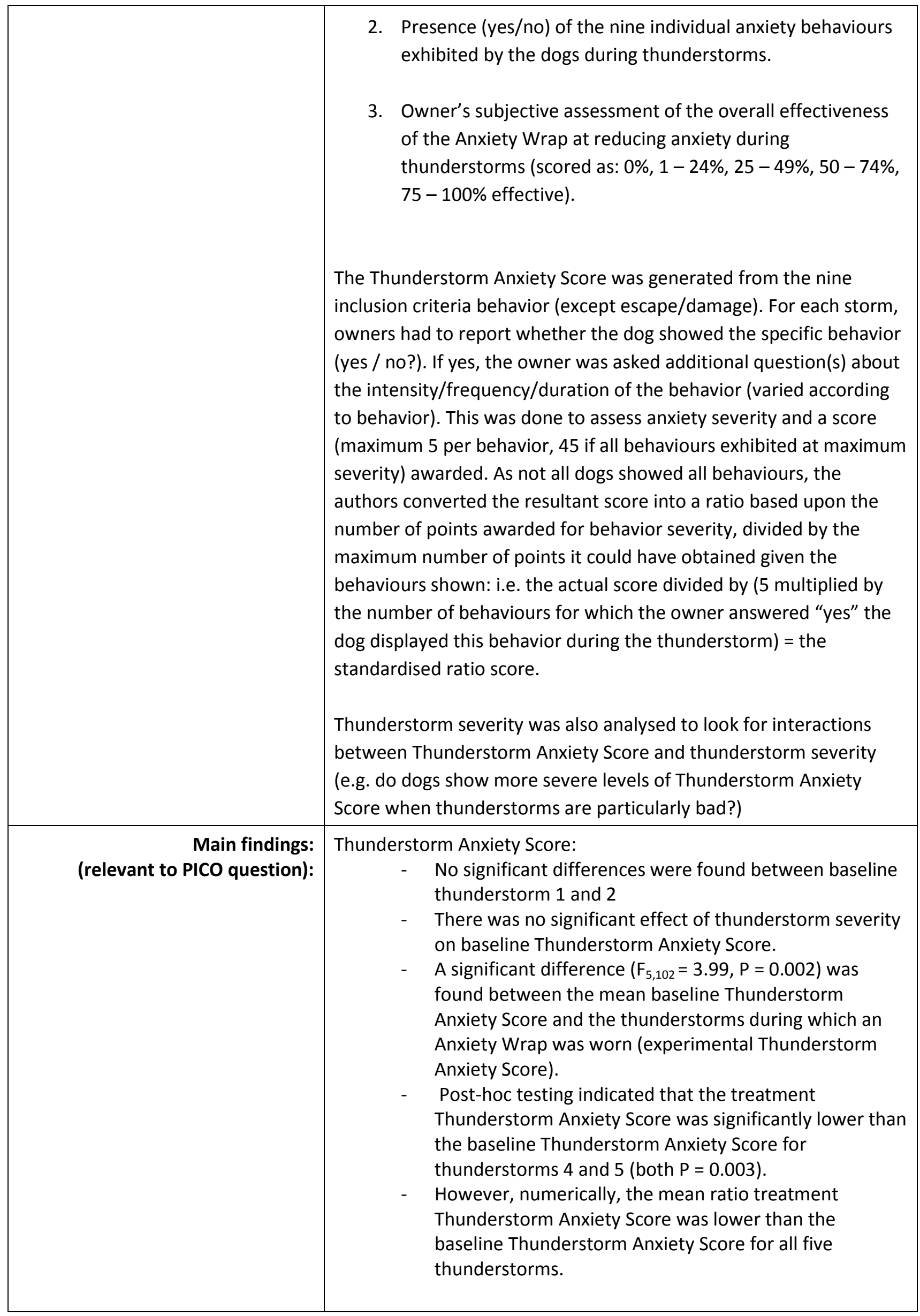




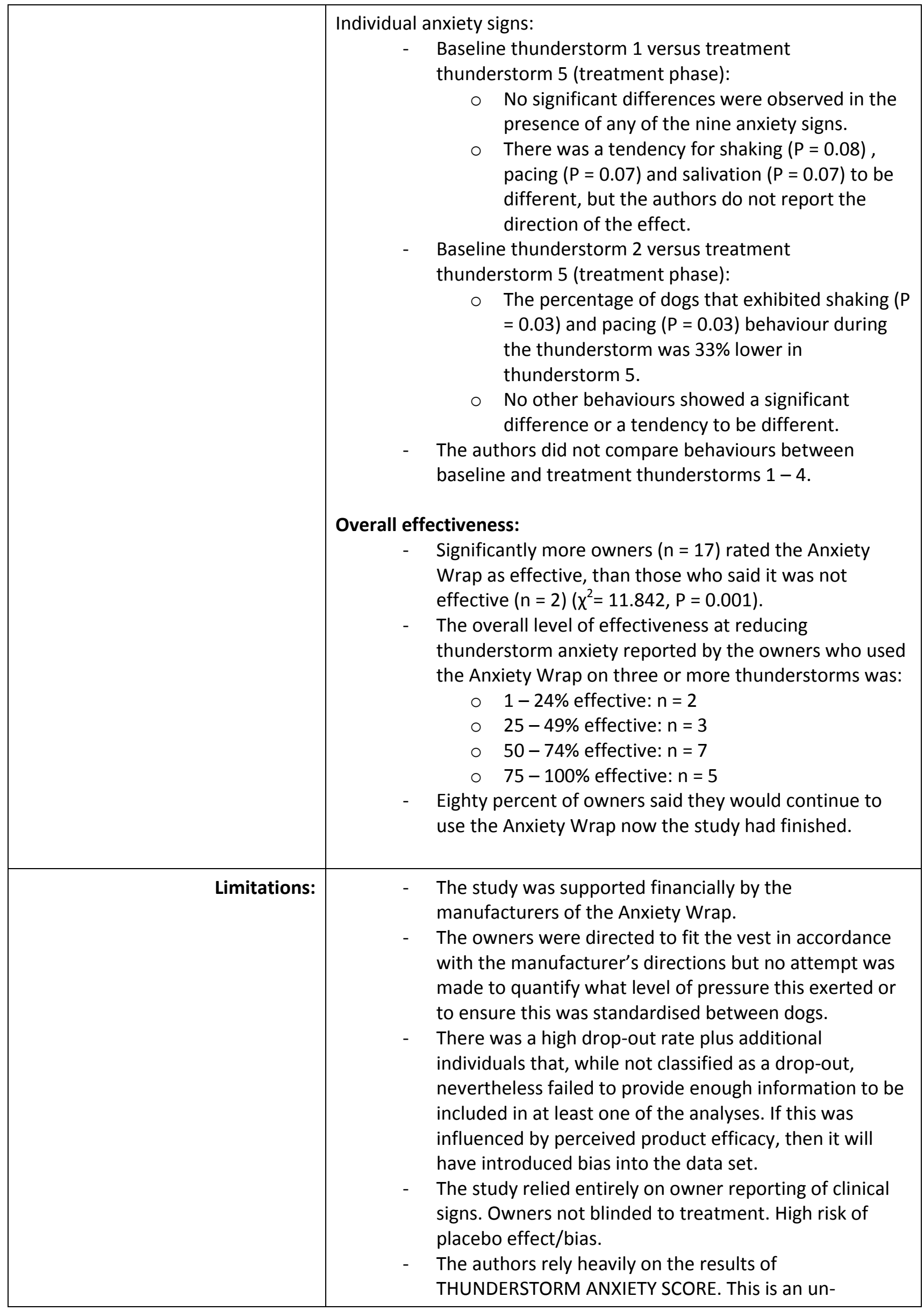




\begin{tabular}{|c|c|}
\hline & $\begin{array}{l}\text { validated method for assessing canine anxiety during a } \\
\text { thunderstorm. } \\
\text { The analysis and reporting of the individual behaviours } \\
\text { could be improved. It is not clear why the authors chose } \\
\text { to analyse each baseline measurement separately } \\
\text { (instead of the mean of both), but this meant that } 18 \\
\text { tests needed to be performed. No allowance has been } \\
\text { made for this statistically (e.g. by applying a Bonferroni } \\
\text { correction). } \\
\text { The authors report that for the two behaviours that } \\
\text { were significantly reduced between baseline } 2 \text { and } \\
\text { treatment thunderstorm 5, that there was a } 33 \% \\
\text { reduction in owners reporting each of these two } \\
\text { behaviours, but it is not clear how much of a reduction } \\
\text { this represents in numerical terms (i.e. how many } \\
\text { owners/dogs stopped seeing these signs?). } \\
\text { Some of the discussion does not match up with the } \\
\text { tables that the text signposts the reader towards. }\end{array}$ \\
\hline \multicolumn{2}{|l|}{ King (2014) } \\
\hline Population: & $\begin{array}{l}\text { Anxious juvenile and adult (i.e. }>6 \text { months) pet dogs with no other } \\
\text { health problems. } \\
\text { To qualify as "anxious" dogs needed to be diagnosed by a } \\
\text { veterinarian or animal behaviourist as having one of the following } \\
\text { conditions: } \\
\quad \text { - Separation Anxiety (SA) } \\
\text { - Generalised Anxiety Condition (GAC) } \\
\text { No breed restrictions were in place and the dogs used were a variety } \\
\text { of sizes and breeds or crossbreeds. Some dogs were on anti-anxiety } \\
\text { medications at the time of the study. }\end{array}$ \\
\hline Sample size: & $\begin{array}{l}\text { Total number of dogs used: } 90 \text { (SA: } n=50 ; G A C: n=40 \text { ), with } 30 \\
\text { dogs per treatment group. }\end{array}$ \\
\hline Intervention details: & $\begin{array}{l}\text { The intervention that was evaluated for efficacy was the } \\
\text { Thundershirt }{ }^{\circledR} \text { (a commercially available pressure vest). } \\
\text { Dogs were randomly allocated to one of three treatment groups (all } \\
\mathrm{n}=30 \text { ): } \\
\text { 1. Control group (no pressure vest worn) } \\
\text { 2. Snug fit vest (pressure vest worn and fitted snugly, as per the } \\
\text { manufacturer's instructions) } \\
\text { 3. Loose fit vest (pressure vest worn and fitted very loosely so } \\
\text { that it exerted no pressure) } \\
\text { All dogs also wore a heart rate monitor strapped over their chest. } \\
\text { Experimental design: }\end{array}$ \\
\hline
\end{tabular}




\begin{tabular}{|c|c|}
\hline & $\begin{array}{l}\text { the pressure vest) } \\
\text { - } \quad \text { A 1-minute baseline heart rate was recorded } \\
\text { - } \text { in this kennel for } 15 \text { minutes } \\
\text { - While the dog was in the kennel their behaviour was video } \\
\text { recorded for later analysis } \\
\text { - Immediately after putting the dog into the kennel, owner } \\
\text { and experimenter left the room and monitored the dog's } \\
\text { response remotely } \\
\text { - Each dog was tested individually and the kennel cleaned } \\
\text { before the next dog was tested. } \\
\text { The outcome measures studied (heart rate and behaviour) are } \\
\text { detailed below. } \\
\text { - Heart rate was measured non - invasively and remotely } \\
\text { using a heart rate monitor. } \\
\text { Behaviour was video recorded and each video watched } \\
\text { independently by two researchers. The researchers were not } \\
\text { blinded to the treatment received. Observations recorded by } \\
\text { each were assessed for inter-observer agreement and } \\
\text { correlations between the behaviour assessments were good } \\
\text { for most parameters ( } r_{\text {average }}=0.99 \text { ) (exception: licking, } r= \\
\text { 0.64). }\end{array}$ \\
\hline Study design: & Randomised controlled trial \\
\hline Outcome studied: & $\begin{array}{l}\text { 1. Heart rate (average heart rate and maximum heart rate) } \\
\text { - Baseline (before entering kennel) } \\
\text { - Experimental (during the } 15 \text { minutes housed in kennel) } \\
\text { 2. Behavioural signs of anxiety (pacing, panting, yawning, } \\
\text { tongue-flicking, drooling, elimination, barking, stress- } \\
\text { whining, howling, licking, orientation towards door) or non- } \\
\text { anxiety (calm presentation) }\end{array}$ \\
\hline $\begin{array}{l}\text { Main findings: } \\
\text { (relevant to PICO question): }\end{array}$ & $\begin{array}{l}\text { Average heart rate: } \\
\text { - There was a significant interaction }\left(\mathrm{F}_{2,1618.93}=8.53, \mathrm{P}<0.01\right) \\
\text { between time (change in HR between baseline } \\
\text { measurement and HR averaged over the } 15 \text {-minute period } \\
\text { of kenneling) and treatment group. } \\
\text { - } \\
\text { Post-hoc, pairwise comparisons indicated that the change in } \\
\text { HR over time of snug fit vest dogs differed from both control } \\
\text { groups }(\mathrm{P}=0.022) \text { and loose fit vest dogs }(\mathrm{P}=0.001) \text {. } \\
\text { - } \text { Snug fit dogs showed a decrease in HR over time; the other } \\
\text { two groups showed an increase in average heart rate. } \\
\text { - Removal of the dogs on anxiety medication (New treatment } \\
\text { group sample sizes: Control: } \mathrm{n}=27 ; \text { Snug fit: } \mathrm{n}=21 ; \text { Loose fit: } \\
\mathrm{n}=25) \text {, and re-analysis of the remaining data found the } \\
\text { same direction of effect, with snug fit dogs differing from }\end{array}$ \\
\hline
\end{tabular}




\begin{tabular}{|c|c|}
\hline & $\begin{array}{l}\text { both control dogs }(P<0.001) \text { and loose fit dogs }(P<0.001) \text {. } \\
\text { Maximum heart rate: } \\
\text { - Significant differences in increase in maximum heart rate } \\
\text { (from baseline) were found between groups }\left(F_{2,86}=4.51, P=\right. \\
\text { 0.01). Post-hoc testing indicated that snug fit dogs had a } \\
\text { lower maximum heart rate increase than loose fit dogs ( } \mathrm{P}= \\
\text { 0.02); but neither experimental group differed significantly } \\
\text { from control dogs. } \\
\text { The author's report removal of the dogs on anxiety } \\
\text { medication (Numbers removed from each group: Control: } n \\
=3 ; \text { Snug fit: } n=9 ; \text { Loose fit: } n=5) \text {, and re-analysis of the } \\
\text { remaining data but they then describe this data in terms of } \\
\text { average heart rate (despite starting off describing the } \\
\text { analysis in terms of maximum heart rate). Therefore, it is not } \\
\text { clear what they are reporting here (average or maximum) } \\
\text { and so it is not reported here. } \\
\text { Behavioural signs of anxiety: } \\
\text { The only behavioural parameter that was significantly } \\
\text { different ( } P=0.02) \text { between groups was orientation towards } \\
\text { the kennel door. Ninety percent of control dogs orientated } \\
\text { towards the door, whereas only } 53 \% \text { of snug fit vest dogs } \\
\text { and } 67 \% \text { of loose fit vest dogs did. } \\
\text { The authors report that the dogs in the snug fit vest group } \\
\text { showed a statistical tendency to show less yawning and } \\
\text { tongue flicking compared to the other two treatment groups } \\
\text { but the statistical handling of this data is problematic (see } \\
\text { limitations). }\end{array}$ \\
\hline Limitations: & $\begin{array}{l}\text { The authors report a statistical tendency for dogs in the snug } \\
\text { fit vest group to show less yawning and tongue flicking. } \\
\text { However, this claim is based upon a Kruskal Wallis test } \\
\text { which indicates that a significant difference exists between } \\
\text { the medians of at one least of the treatment pairs (but not } \\
\text { one(s)). The authors do not undertake post-hoc testing. } \\
\text { - Despite reporting, this behavioural data was often highly } \\
\text { skewed, they present this data using means and standard } \\
\text { deviations which conceals the true spread of values. } \\
\text { - The owners were directed to fit the vest in accordance with } \\
\text { the manufacturer's directions (snug fit dogs only) but no } \\
\text { attempt was made to quantify what level of pressure this } \\
\text { exerted or to ensure this was standardised between dogs. } \\
\text { Two types of anxiety condition were accepted under the } \\
\text { inclusion criteria, but no attempt was made to undertake a } \\
\text { randomised block design in which each condition was } \\
\text { equally/near equally distributed across the three treatment } \\
\text { conditions. } \\
\text { Observers were not blinded to treatment. } \\
\text { Dogs were not habituated to vest wearing before the study. } \\
\text { The baseline heart rate measurement was recorded after } \\
\text { the pressure vest was fitted, and both loose and snug fit }\end{array}$ \\
\hline
\end{tabular}




\begin{tabular}{|c|c|}
\hline & $\begin{array}{l}\text { groups had a mean baseline heart rate that was numerically } \\
\text { higher (the authors do not report analysing baseline group } \\
\text { differences) than the control group, suggesting that the vest } \\
\text { was initially anxiety-inducing. }\end{array}$ \\
\hline \multicolumn{2}{|l|}{ Pekkin (2016) } \\
\hline Population: & $\begin{array}{l}\text { Finnish-based adult dogs (various breeds, both genders and either } \\
\text { neuter status) known to usually ( } 60-100 \% \text { of occasions) react } \\
\text { fearfully to fireworks. } \\
\text { Firework fear was assessed using a validated questionnaire (Tiira \& } \\
\text { Lohi, 2014) that had a good test-retest reliability when assessing } \\
\text { noise-related fears. The questionnaire was completed by the dogs' } \\
\text { owners. The questionnaire provided the authors with a measure of } \\
\text { the dogs' noise reactivity, noise fear frequency, and general } \\
\text { fearfulness. } \\
\text { Exclusion criteria: fear towards strange people or situations, bitches } \\
\text { in season, dogs using regular medication (other than non-steroid } \\
\text { anti-inflammatories). }\end{array}$ \\
\hline Sample size: & $\begin{array}{l}28 \text { dogs were recruited to the study. } \\
\text { A full set of data was not collected for each dog. For the oxytocin } \\
\text { analysis, two urine samples were obtained from } 24 \text { of the dogs. For } \\
\text { the cortisol analysis, four saliva samples were obtained from } 20 \\
\text { dogs. For the behavioural analysis, } 25 \text { dogs participated in all tests. }\end{array}$ \\
\hline Intervention details: & $\begin{array}{l}\text { The intervention that was evaluated for efficacy was the Lymed } \\
\text { Animal }{ }^{\text {TM }} \text { Supporting Garments (a commercially available pressure } \\
\text { vest). } \\
\text { There were three treatment groups, with each dog planned to } \\
\text { experience each of the treatments. The three treatment groups } \\
\text { were: } \\
\text { 1. Control (no pressure vest fitted) } \\
\text { 2. Light pressure (pressure vest fitted lightly, exerting a } \\
\text { pressure on the dog of approximately } 2-3 \mathrm{mmHg} \text { ) } \\
\text { 3. Deep pressure (pressure vest fitted firmly, as per the } \\
\quad \text { manufacturers' recommendations, and exerting a pressure } \\
\text { on the dog of approximately } 10-12 \mathrm{mmHg} \text { ) } \\
\text { Dogs were semi-randomly allocated (balanced for gender) to one of } \\
\text { three groups, with each group experiencing the three treatments in } \\
\text { a different order. } \\
\text { The study was divided into three main sections: }\end{array}$ \\
\hline
\end{tabular}




\begin{tabular}{|c|c|}
\hline & 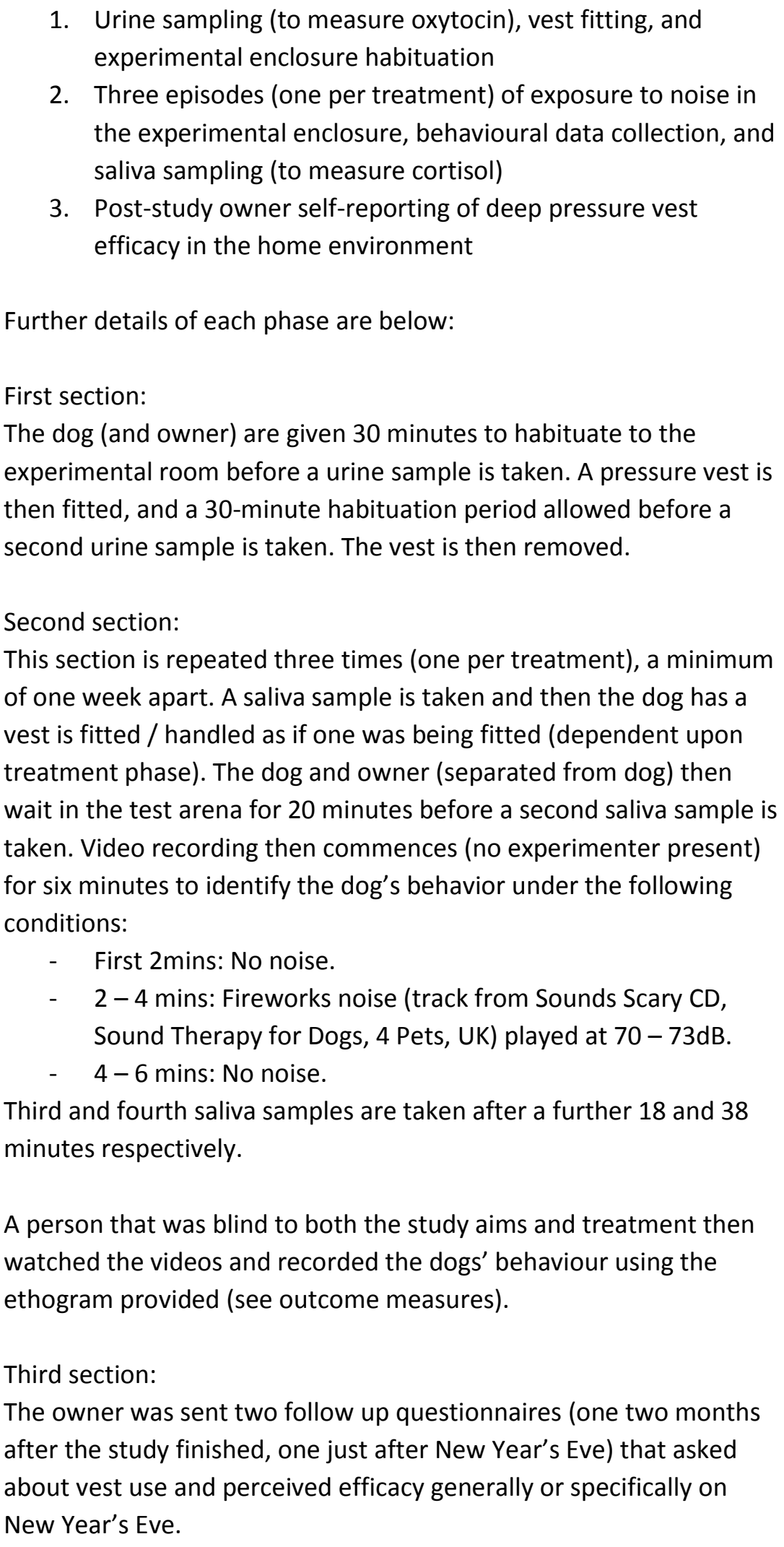 \\
\hline Study design: & Randomised controlled trial \\
\hline Outcome studied: & $\begin{array}{l}\text { The outcome measures studied that were relevant to addressing the } \\
\text { PICO included: } \\
\text { Physiological: }\end{array}$ \\
\hline
\end{tabular}




\begin{tabular}{|c|c|}
\hline & $\begin{array}{l}\text { 1. Urinary oxytocin levels } \\
\text { 2. Saliva cortisol levels } \\
\text { Behavioural: } \\
\text { 1. Body positions } \\
\text { 2. Lying } \\
\text { 3. Sitting } \\
\text { 4. Standing } \\
\text { 5. Motor activity - fence manipulation } \\
\text { 6. Tail position } \\
\text { 7. Location } \\
\text { 8. Location in arena (divided into grids) } \\
\text { 9. Location in relation to a table (under table? Yes / no) } \\
\text { 10. Vocalisation } \\
\text { 11. Oral behaviours } \\
\text { 12. Lick nose or lips } \\
\text { 13. Pant } \\
\text { 14. Other - trembling } \\
\text { Owner self - reporting (survey data): } \\
\text { 1. Did the owners use the vest during daily life? } \\
\text { 2. Did the owners use the vest on their dog on New Year's } \\
\text { 3. Deve? }\end{array}$ \\
\hline $\begin{array}{l}\text { Main findings: } \\
\text { (relevant to PICO question): }\end{array}$ & $\begin{array}{l}\text { Selected findings (directly relevant to the PICO): } \\
\text { Physiological: } \\
\text { 1. Oxytocin: } \\
\text { - There was no significant effect of wearing a deep pressure } \\
\text { vest on urinary oxytocin levels. } \\
\text { 2. Cortisol: } \\
\text { - There was no significant effect of treatment on saliva } \\
\text { cortisol levels. However, saliva cortisol levels were } \\
\text { significantly higher } 20 \text { minutes after the fireworks CD } \\
\text { finished playing (cortisol sample } 3 \text { ), than immediately before } \\
\text { the noise test (cortisol sample } 2 \text { ), or after a } 40 \text {-minute } \\
\text { recovery period (cortisol sample } 4) \text {. } \\
\text { Behavioural: } \\
\text { Dogs spent less time lying down during the two-minute } \\
\text { period during which the fire work noise was being played } \\
\text { when they were wearing the deep pressure vest, compared } \\
\text { to when they were wearing no vest (control) }(P<0.03) \text {. The } \\
\text { median (interquartile range) seconds spent lying down was: } \\
\text { deep pressure: } 0.0 \text { ( } 66.9 \text { ); light pressure: } 12.7 \text { (110.1); } \\
\text { control: } 39.0 \text { (209.0). } \\
\text { There was a positive correlation between duration of time }\end{array}$ \\
\hline
\end{tabular}




\begin{tabular}{|c|c|}
\hline & $\begin{array}{l}\text { spent lying down and general fearfulness }(P<0.05) \text { and } \\
\text { noise fear frequency }(P<0.05) \text {. } \\
\text { - No other behavioural treatment effects were identified }(P> \\
\text { 0.05). } \\
\text { Owner reports: } \\
\text { - } \text { Of the } 28 \text { owners who completed the first post-study survey, } \\
17 \text { had used the pressure vest at home. Of these, } 14 \\
\text { reported that its use had mainly positive effects, and three } \\
\text { were neutral. } \\
\text { Of the } 26 \text { owners who completed the second post-study } \\
\text { survey (regarding its use on New Year's Eve), } 20 \text { dogs had } \\
\text { worn the vest on New Year's Eve. Of these, } 16 \text { reported } \\
\text { positive effects, and four were neutral about its use. }\end{array}$ \\
\hline Limitations: & $\begin{array}{l}\text { - Authors report semi-randomly allocating dogs to the order } \\
\text { of treatment, but do not report what they mean by 'semi' or } \\
\text { how this was achieved. } \\
\text { - Only } 25 \text { dogs took part in all three treatments. However, the } \\
\text { authors report using all } 28 \text { dogs in the analysis. This may } \\
\text { have introduced bias into the study. They fail to report in } \\
\text { sufficient detail which dogs dropped out, at what stage, and } \\
\text { which treatment(s) they had completed (i.e. were included } \\
\text { in the statistical analysis) and which they hadn't. } \\
\text { - Behavioural outcome measures were often proxy measures } \\
\text { that do not necessarily measure anxiety. } \\
\text { - Exposure to the firework stimulus acted as a very short } \\
\text { acute stimulus and may not represent the normal conditions } \\
\text { under which a dog is exposed to noise stressors like } \\
\text { fireworks. } \\
\text { The study reports that the observer was blinded to } \\
\text { treatments but it is not clear how that blinding was achieved } \\
\text { (e.g. were the vest images pixelated? Did the authors mean } \\
\text { blinded to when the audio-recording was being played?). } \\
\text { The study was supported financially by the manufacturer of } \\
\text { the pressure vest used in the study. }\end{array}$ \\
\hline \multicolumn{2}{|l|}{ Fish (2017) } \\
\hline Population: & $\begin{array}{l}\text { Adult, male and female field-trial-bred Labrador Retrievers } \\
\text { purchased by a military training facility and kennel housed at the } \\
\text { research facility that carried out this study. Dogs had been used in } \\
\text { previous studies, including one using telemetry vests and one } \\
\text { utilizing the Open-field Test (OFT). }\end{array}$ \\
\hline Sample size: & 16 dogs (8 per treatment group) \\
\hline Intervention details: & $\begin{array}{l}\text { The intervention was the wearing of a telemetry vest during testing } \\
\text { within the OFT. } \\
\text { Two treatment groups: } \\
\text { 1. Vest }(n=8)\end{array}$ \\
\hline
\end{tabular}




\begin{tabular}{|c|c|}
\hline & $\begin{array}{l}\text { 2. No Vest ( } \mathrm{n}=8 \text { ) } \\
\text { Each dog was given three OFTs, held on three consecutive days, and } \\
\text { each of nine minutes duration. During tests one and three, dogs } \\
\text { were exposed to no auditory stimuli while in the OFT area. During } \\
\text { test two, dogs were exposed to a thunderstorm audio recording } \\
\text { during the middle three minutes of the nine-minute test. Dogs were } \\
\text { filmed during the OFT for later anxiety scoring using one partially- } \\
\text { blinded, trained observer (blind to thunderstorm stimulus } \\
\text { occurrence, not blind to vest wearing). Immediately prior to each } \\
\text { OFT, a telemetry vest was fitted to each dog, and the dog's heart } \\
\text { rate and temperature were then manually recorded. The vest was } \\
\text { then left on (Vest dogs) or removed (No Vest dogs) for the OFT. } \\
\text { Immediately after the OFT, the dog's heart rate and temperature } \\
\text { were manually recorded again. } \\
\text { Further detail: } \\
\text { The spandex vest was standardised for pressure by fitting the vest to } \\
\text { each dog tight enough to only allow two fingers to be inserted under } \\
\text { the vest. } \\
\text { Dogs were allocated to treatment group using a randomised match- } \\
\text { pairs design. They were pair ranked (lowest to highest value) } \\
\text { according to their Global Anxiety Score (obtained in a previous study, } \\
\text { Gruen et al. 2015), and then the first of each pair member randomly } \\
\text { allocated to either the Vest or No Vest group, and the remaining pair } \\
\text { member allocated to the alternative group. }\end{array}$ \\
\hline Study design: & Randomised controlled trial \\
\hline Outcome studied: & $\begin{array}{l}\text { Outcomes relevant to addressing the PICO included: } \\
\text { Physiological data: } \\
\text { 1. Heart rate (beats per minute, bpm) } \\
\text { 2. Rectal temperature (centigrade, }{ }^{\circ} \mathrm{C} \text { ) were recorded } \\
\text { immediately after fitting the vest (both treatment groups, } \\
\text { just before entering the OFT arena) and immediately after } \\
\text { the nine-minute OFT. } \\
\text { Behavioural data: } \\
\text { 1. Mean Anxiety Score during each three-minute period of the } \\
\text { OFT. } \\
\text { Anxiety assessment was subjective and based on a } \\
\text { subjective qualitative ordinal scale ( } 1-6,1=\text { no anxiety } \\
\text { behaviours observed, } 6=\text { severe anxiety observed most of } \\
\text { the time). } \\
\text { Dogs were initially scored separately for negative/passive } \\
\text { anxiety (e.g. freezing, hiding, etc) and positive/active anxiety }\end{array}$ \\
\hline
\end{tabular}




\begin{tabular}{|c|c|}
\hline & $\begin{array}{l}\text { (e.g. escape attempts, bolting, etc). The mean of these two } \\
\text { scores was used in the analysis. }\end{array}$ \\
\hline $\begin{array}{l}\text { Main findings: } \\
\text { (relevant to PICO question): }\end{array}$ & $\begin{array}{l}\text { Findings relevant to the PICO: } \\
\text { Physiological data: } \\
\text { 1. Heart rate: } \\
\text { - } \text { On OFT days (pooled data from the three days), Vest dogs } \\
\text { had significantly ( } F=11.7, \mathrm{P}=0.0009 \text { ) lower heart rates than } \\
\text { No Vest dogs. The mean (standard error of the mean, s.e.m.) } \\
\text { was: Vest dogs: } 95.5 \text { ( } \pm 1.5 \text { bpm); No Vest dogs: } 103.9 \text { ( } \pm 2.0 \\
\text { bpm). } \\
\text { 2. Rectal temperature: } \\
\text { - On OFT days (pooled data), mean rectal temperature did not } \\
\text { differ between Vest dogs and No Vest dogs. The mean } \\
\text { (s.e.m.) temperature was: Vest dogs: } 39.1\left( \pm 0.1^{\circ} \mathrm{C}\right) \text {; No Vest } \\
\left.\text { dogs: } 39.0 \text { ( } \pm 0.2^{\circ} \mathrm{C}\right) \text {. } \\
\text { Behavioural data: } \\
\text { 1. Mean Anxiety Score: } \\
\text { On OFT days (pooled data), the MAS of Vest dogs was } \\
\text { significantly ( } \mathrm{F}=0.241 .3, \mathrm{P}=0.0031 \text { ) lower than No Vest } \\
\text { dogs. The overall (mean, } \pm \text { s.e.m.) MAS was: Vest dogs: } 1.9 \pm \\
\text { 0.4; No Vest dogs: } 2.9 \pm 0.4(\mathrm{~T}=-1.80, \mathrm{P}=0.0471 \text { ). } \\
\text { There was a statistically significant (no test statistic } \\
\text { reported, } \mathrm{P}<0.05 \text { ) difference between Vest and No Vest } \\
\text { dogs in terms of the change in MAS between the pre-phase } \\
\text { and the during-phase of day } 2 \text {. Vest dogs had a } 40 \% \text { lower } \\
\text { MAS during the thunderstorm stimulus than No Vest dogs. }\end{array}$ \\
\hline Limitations: & $\begin{array}{l}\text { The most severe limitation is the reporting that heart rate } \\
\text { was higher in No Vest dogs, but the pre-OFT heart rate was } \\
\text { taken while both Vest and No Vest dogs were wearing the } \\
\text { vest (i.e. dogs were being treated identically at this point). } \\
\text { The authors do not report accounting for this issue in their } \\
\text { data handling (e.g. by only using post OFT heart rate data). } \\
\text { - Pairwise comparisons were performed using a one-tailed } \\
\text { Student t-test. The authors report adopting this approach } \\
\text { because of their directional hypothesis, but it is possible that } \\
\text { Vest wearing could have had the opposite effect and this } \\
\text { would also be clinically relevant to the study's aim. The } \\
\text { analysis and reporting would have been more robust if a } \\
\text { two-tailed approach had been taken. If it had been adopted, } \\
\text { the overall mean MAS would not have been significant as } \\
\text { the P value would have been P = 0.0942. } \\
\text { Some data reporting is not precise enough to allow the } \\
\text { reader to determine how the data was handled/being } \\
\text { reported. For example, what does "overall" MAS mean? } \\
\text { How was it determined? } \\
\text { The authors report using data pooled from the three days } \\
\text { for some of the statistical analyses, but they do not report } \\
\text { how this data was pooled or the rationale for this. } \\
\text { It was a very small sample size ( } \mathrm{n}=8 \text { per treatment) and the }\end{array}$ \\
\hline
\end{tabular}




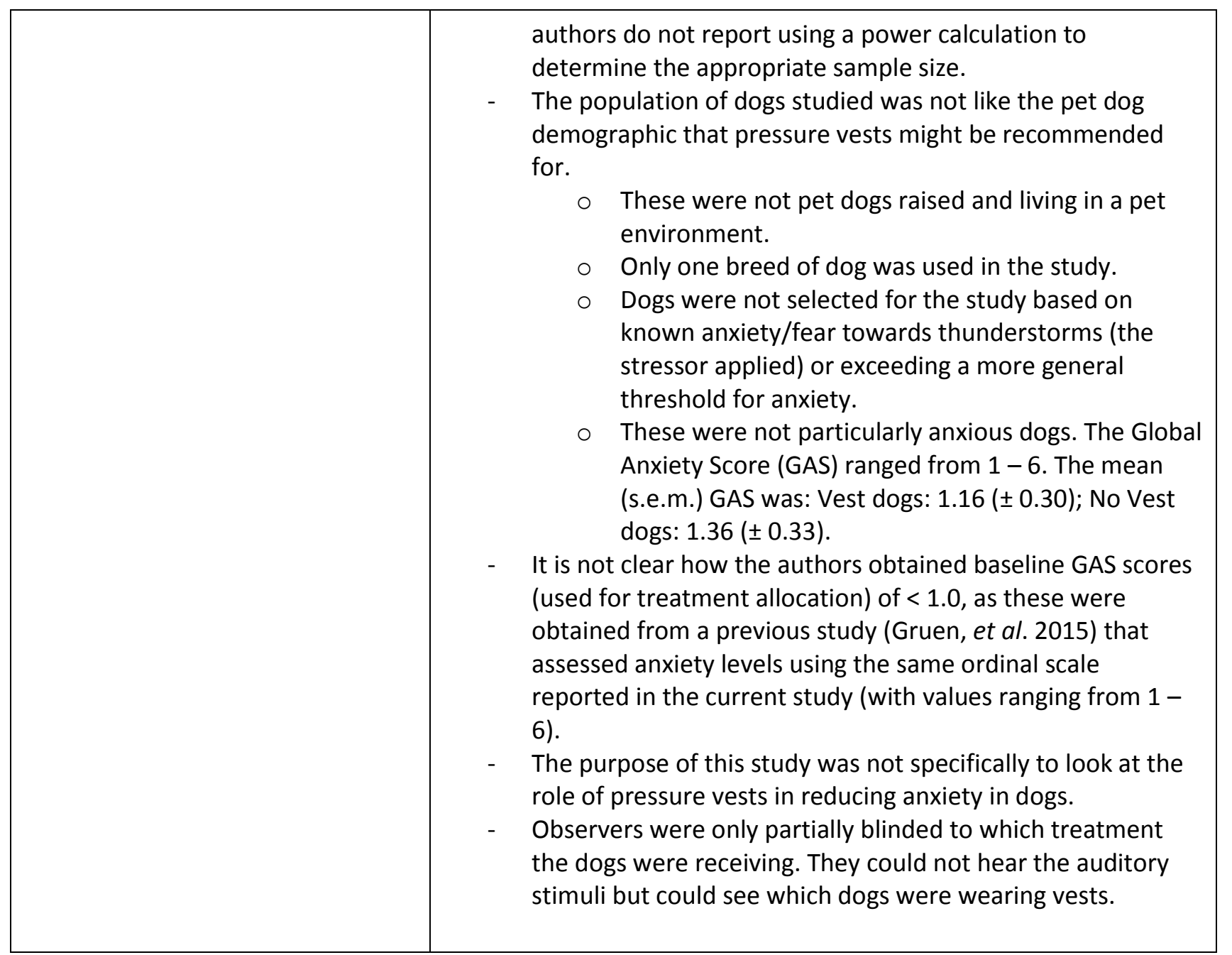

\section{Appraisal, application and reflection}

In terms of external relevance, of the studies that were included, three of the papers (Cottam et al., 2013; Pekkin et al., 2016; Fish et al., 2017) used noise stressors (thunderstorm, firework or thunderstorm sound recordings respectively) to induce an anxiety or fear response. The stressors have external relevance as thunderstorms, fireworks and separation-related stress are all stressors that clients will frequently approach veterinary professionals to seek assistance with the management or treatment of their dog's negative response towards. However, whilst the Cottam et al. (2013) study used field data based on known thunderstorm-fearful dogs' responses to actual thunderstorms whilst in their home environment, the other studies used study designs that may have reduced the applicability of the study findings in a real-life scenario. The three studies investigating commercially available pressure vests all selected pet dogs drawn from a population of dogs known to be fearful or anxious of either the sound stressor used in the study (Cottam et al., 2013; Pekkin et al., 2016) or of having separation anxiety or a generalised anxiety disorder relevant to triggering anxiety under the isolation kennel facilities (King et al., 2014). Thus, applicability to client-owned dogs is likely to be good from this perspective. The Fish et al. (2017) study was more problematic in this respect. These were kennelled dogs, drawn from military working dogs and housed under research conditions. Although the dogs were scored using a global anxiety score (scores carried over from a previous study, Gruen et al., 2015) this was undertaken to allocate dogs evenly across treatment groups, and being anxious (either specifically in response to thunderstorms or more generally) was not part of any inclusion criteria. Although dogs per se will clearly all experience fear and anxiety at some point (and the data in this study indicates that these dogs did show an increase in their anxiety score during testing compared with the mean global anxiety 
score), clients seeking assistance or advice may be disproportionately drawn from dogs known to be fearful or anxious (or, more severely so) in the presence of a given stressor. Thus, the dogs studied in this study may differ from those we wish to apply any findings too and this should be borne in mind.

In terms of internal validity, each of the studies had its merits and limitations. The Cottam et al. (2013) study was a field-based, clearly client-relevant, commercially funded study that relied heavily on owner reporting of behaviour. The authors reported that the use of a pressure vest, compared with baseline measurements, was associated with a numerical reduction on the anxiety scores during all thunderstorms in the treatment phase. However, only during treatment thunderstorms 4 and 5 , was the mean anxiety score sufficiently lower than the baseline anxiety score for any potential difference to be significant. This downward trend in anxiety scores may suggest that there may be an element of associative learning to any therapeutic effect of pressure vest use. Owners reported a variable level of efficacy, but most owners felt that the vest had some positive effect on their dog's thunderstorm fear. However, the owners were not blinded to treatment, and thus there is a high risk of placebo effect or bias being present in the reporting of these results. However, with a cautionary note that the Thunderstorm Anxiety Score is an un-validated method for quantifying thunderstorm anxiety severity, this study does provide some limited evidence of a beneficial effect of pressure vests on dog anxiety during thunderstorms.

The King et al. (2014) paper used a positive control (loose fitting vest) as well as a traditional control group that allowed the authors to identify whether any apparent benefit of wearing a pressure vest was due to simply wearing an item of clothing (e.g. dogs associated it with going for a pleasant walk) or genuinely an effect of pressure exerted on the dog's torso. The strongest finding in this study was the demonstration that dogs in the snug fit vest group showed a decrease in heart rate between the baseline (pre-kennel/isolation) and the average heart rate of the dog when in the kennel for 15 minutes. This contrasted with both other treatment groups which demonstrated the converse. The behavioural data also demonstrated that snug fit dogs spent less time orientating towards the door (53\% of dogs, as compared to $67 \%$ of loose fit dogs, and $90 \%$ of control dogs). This is more problematic to interpret as this would suggest that wearing a vest per se reduced door orientation behaviour. These dogs were not habituated to pressure vest wearing at the start of the study and the authors do not report information regarding the dogs' prior coat-wearing history so it is difficult to assess the likelihood of this alternative interpretation. The authors report a statistical tendency for snug fit dogs to show less yawning and tongue flicking but their statistical handling and reporting of this data made it more problematic to draw conclusions from the behavioural output. They report the data was highly skewed and use a non-parametric test to undertake inferential testing but then report the data using the mean ( \pm standard deviation) which makes independent interpretation of the data problematic. However, the study does provide some evidence that a pressure vest can reduce a physiological measure of arousal during short term isolation from the owner/confinement to an unfamiliar area.

Also commercially funded, the Pekkin et al. (2016) study found very little evidence of pressure vests having a beneficial effect in their main study (though the owners, when surveyed, subsequently reported a positive effect under field conditions). No physiological parameters (oxytocin, cortisol) were affected by wearing a pressure vest (either fitted loosely or firmly), but the cortisol levels increased post-audio stressor across all treatment groups, suggesting that the dogs did find the audio-stressor stressful. However, when the dogs were wearing a firmly fitted vest they spent less time laying down during the audio-stressor than under either other treatment condition, and laying down behaviour was (independent of treatment) shown to be positively correlated with fear. This might indicate that, when wearing a firmly fitted vest, dogs felt less fearful during the audio recording of fireworks. However, it cannot be discounted that lying down in a tight-fitting vest is less comfortable than when wearing a vest loosely or no vest at all. No other behaviour parameters were affected by treatment. The weakest part of this study was the owner survey which was very sensitive to bias and the placebo effect. However, the main study may provide some very limited evidence that firmly fitted pressure vests may have a positive impact on one behavioural sign of canine anxiety, but this would be more convincing if more of the outcome variables were affected by a firmly fitted pressure vest and more research is needed here.

The Fish et al. (2017) study reported that the use of a telemetry vest resulted in a lower heart rate, lower anxiety scores during the open field tests and reduced increase in anxiety score during the audio recording of thunder, compared with dogs not wearing a vest. However, a small sample size ( $n=8$ per group) and 
methodological issues reduce the reliability of these findings (particularly, the significant difference in heart rates between treatment groups). Further research, using a large sample size (determined using a power calculation) would be beneficial here.

In conclusion, four studies of variable quality and limitations were identified that investigated the use of pressure vests, using various physiological and behavioural proxy measures of anxiety. Most behavioural outcome measures associated with a positive effect were subjective assessments, with unblinded assessors. Differences between study designs, stressors and outcome measures used, and what parameters were affected by pressure vest wearing make it difficult to meaningfully triangulate findings and draw firmer conclusions. The take home message for the veterinary professional is that pressure vests may have small but beneficial effects on canine anxiety and that habituating the dog to the vest, assessing for comfort and using repeatedly may improve the likelihood of any benefit. However, the owner should be cautioned that they should not expect their dog's anxiety to be fully alleviated or prevented, and it may have no beneficial effect at all.

\section{Methodology Section}

\begin{tabular}{|c|c|}
\hline $\begin{array}{r}\text { Databases searched and dates } \\
\text { covered: }\end{array}$ & $\begin{array}{l}\text { Pubmed (1900 - 14/09/2017); Science Direct }(1901-14 / 09 / 2017) \text {; } \\
\text { CAB Abstracts }(1973-2017 \text {, week } 35)\end{array}$ \\
\hline Search terms: & $\begin{array}{l}\text { Pubmed: } \\
\text { (dog OR dogs OR canine OR bitch OR bitches OR canid OR puppy OR } \\
\text { puppies) AND (vest OR shirt OR jacket OR coat OR wrap OR cape) } \\
\text { AND (anxiety OR anxious OR fear OR fearful OR stress OR stressed } \\
\text { OR stressful OR panic OR phobi*) } \\
\text { Science Direct: } \\
\text { Restricted to: <Advanced search><journals only><title-abstr-key> } \\
\text { (dog OR dogs OR canine OR bitch OR bitches OR canid OR puppy OR } \\
\text { puppies) AND (vest OR shirt OR jacket OR coat OR wrap OR cape) } \\
\text { AND (anxiety OR anxious OR fear OR fearful OR stress OR stressed } \\
\text { OR stressful OR panic OR phobi*) } \\
\text { CAB Abstracts: } \\
1 \text { (dog or dogs or canine or bitch or bitches or canid or puppy or } \\
\text { puppies).mp. [mp=abstract, title, original title, broad terms, heading } \\
\text { words, identifiers, cabicodes] (195323) } \\
2 \text { (vest or shirt or jacket or coat or wrap or cape).mp. [mp=abstract, } \\
\text { title, original title, broad terms, heading words, identifiers, } \\
\text { cabicodes] ( } 40414 \text { ) } \\
3 \text { (anxiety or anxious or fear or fearful or stress or stressed or } \\
\text { stressful or panic or phobi*).mp. [mp=abstract, title, original title, } \\
\text { broad terms, heading words, identifiers, cabicodes] ( } 311937 \text { ) } \\
41 \text { and } 2 \text { and } 3 \text { ( } 36 \text { ) }\end{array}$ \\
\hline Dates searches performed: & $\begin{array}{l}\text { Pubmed: 14/09/2017; Science Direct: 14/09/2017; CAB Abstracts: } \\
\text { 11/09/2017 }\end{array}$ \\
\hline
\end{tabular}




\begin{tabular}{|c|c|c|c|c|c|c|}
\hline \multicolumn{7}{|c|}{ Exclusion / Inclusion Criteria } \\
\hline & Exclusion: & \multicolumn{5}{|c|}{$\begin{array}{l}\text { Pre-defined exclusion criteria: non-English language, popular press } \\
\text { articles, conference abstracts }\end{array}$} \\
\hline & Inclusion: & \multicolumn{5}{|c|}{$\begin{array}{l}\text { Any comparative (control group utilised) study in which the effect of } \\
\text { pressure vests on anxiety (or similar) in dogs was studied. }\end{array}$} \\
\hline \multicolumn{7}{|c|}{ Search Outcome } \\
\hline Database & $\begin{array}{c}\text { Number of } \\
\text { results }\end{array}$ & $\begin{array}{c}\text { Excluded - } \\
\text { did not } \\
\text { answer PICO } \\
\text { question }\end{array}$ & $\begin{array}{c}\text { Excluded - not } \\
\text { English } \\
\text { language }\end{array}$ & $\begin{array}{l}\text { Excluded - } \\
\text { conference } \\
\text { abstract } \\
\text { only }\end{array}$ & $\begin{array}{l}\text { Excluded - } \\
\text { duplicates }\end{array}$ & $\begin{array}{c}\text { Total } \\
\text { relevant } \\
\text { papers }\end{array}$ \\
\hline Pubmed & 41 & 40 & 0 & 0 & 1 & 1 \\
\hline Science Direct & 35 & 32 & 0 & 0 & 0 & 3 \\
\hline CAB Abstracts & 36 & 30 & 0 & 1 & 5 & 0 \\
\hline \multicolumn{6}{|c|}{ Total relevant papers when duplicates removed } & 4 \\
\hline
\end{tabular}

\section{CONFLICT OF INTEREST}

The author declares no conflicts of interest.

\section{REFERENCES}

1. Cottam, N, Dodman, N. H. 2009. Comparison of the effectiveness of a purported anti-static cape (the Storm Defender ${ }^{\circledast}$ ) vs. a placebo cape in the treatment of canine thunderstorm phobia as assessed by owners' reports. Applied Animal Behaviour Science 119: 78 - 84

DOI: https://doi.org/10.1016/j.applanim.2009.03.014

2. Cottam, N., Dodman, N. H., Ha, J. C. 2013. The effectiveness of the Anxiety Wrap in the treatment of canine thunderstorm phobia: An open - label trial. Journal of Veterinary Behaviour 8: $154-161$

DOI: http://dx.doi.org/10.1016/i.jveb.2012.09.001

3. Fish, R.E., Foster, M. L., Gruen, M.E., et al. Effect of wearing a telemetry jacket on behavioral and physiologic parameters of dogs in the Open - field Test. Journal of the American Association for Laboratory Animal Science 56: 382 - 389 
4. Gruen, M. E., Case, B. C., Foster, M. L., et al. The use of an open field model to assess sound-induced fear and anxiety-associated behaviours in Labrador retrievers. Journal of Veterinary Behavior 10: 338 345 DOI: $\underline{10.1016 / \text { i.jveb.2015.03.007 }}$

5. King, C., Buffington L., Smith, T. J., et al. The effect of a pressure wrap (Thundershirt ${ }^{\circledR}$ ) on heart rate and behavior in canines diagnosed with anxiety disorder. Journal of Veterinary Behaviour 9: 215-221 DOI: https://doi.org/10.1016/i.jveb.2014.06.007

6. Pekkin, A., Hänninen, L., Tiira, K. et al. The effect of a pressure vest on the behavior, salivary cortisol and urine oxytocin of noise phobic dogs in a controlled test. Applied Animal Behaviour Science 185: 86 - 94 DOI: https://doi.org/10.1016/j.applanim.2016.09.003

7. Tiira, K., Lohi, H., 2014. Reliability and validity of a questionnaire survey in canine anxiety research. Applied Animal Behaviour Science155: 82 -

92: http://dx.doi.org/10.1016/i.applanim.2014.03.007 


\section{EVIDENCE \\ online}

\section{Intellectual Property Rights}

Authors of Knowledge Summaries submitted to RCVS Knowledge for publication will retain copyright in their work, and will be required to grant to RCVS Knowledge a non-exclusive license of the rights of copyright in the materials including but not limited to the right to publish, re-publish, transmit, sell, distribute and otherwise use the materials in all languages and all media throughout the world, and to license or permit others to do so.

\section{Disclaimer}

Knowledge Summaries are a peer-reviewed article type which aims to answer a clinical question based on the best available current evidence. It does not override the responsibility

of the practitioner. Informed decisions should be made by considering such factors as individual clinical expertise and judgement along with patient's circumstances and owners' values. Knowledge Summaries are a resource to help inform and any opinions expressed within the Knowledge Summaries are the author's own and do not necessarily reflect the view of the RCVS Knowledge.

Veterinary Evidence and EBVM Network are RCVS Knowledge initiatives. For more information please contact us at editor@veterinaryevidence.org

RCVS Knowledge is the independent charity associated with the Royal College of Veterinary Surgeons (RCVS). Our ambition is to become a global intermediary for evidence based veterinary knowledge by providing access to information that is of immediate value to practicing veterinary professionals and directly contributes to evidence based clinical decision-making.

www.veterinaryevidence.org

RCVS Knowledge is a registered Charity No. 230886. Registered as a Company limited by guarantee in England and Wales No. 598443.

Registered Office:

Belgravia House

62-64 Horseferry Road

London SW1P 2AF 